\title{
Seismic Analysis of a Viscoelastic Damping Isolator
}

\author{
Bo-Wun Huang, ${ }^{1}$ Jao-Hwa Kuang, ${ }^{2}$ Jung-Ge Tseng, ${ }^{3}$ Jyun-Cin Wang, ${ }^{1}$ and Yu-Xian Qiu ${ }^{4}$ \\ ${ }^{1}$ Department of Mechanical Engineering, Cheng Shiu University, Kaohsiung 83347, Taiwan \\ ${ }^{2}$ Department of Mechanical Engineering, National Sun Yat-Sen University, Kaohsiung 80424, Taiwan \\ ${ }^{3}$ Department of Leisure and Sports Management, Cheng Shiu University, Kaohsiung 83347, Taiwan \\ ${ }^{4}$ Bachelor Program of Medical Engineering, Cheng Shiu University, Kaohsiung 83347, Taiwan \\ Correspondence should be addressed to Jung-Ge Tseng; james.tseng@csu.edu.tw
}

Received 26 September 2014; Accepted 18 March 2015

Academic Editor: Luigi Nicolais

Copyright (C) 2015 Bo-Wun Huang et al. This is an open access article distributed under the Creative Commons Attribution License, which permits unrestricted use, distribution, and reproduction in any medium, provided the original work is properly cited.

\begin{abstract}
Seismic prevention issues are discussed much more seriously around the world after Fukushima earthquake, Japan, April 2011, especially for those countries which are near the earthquake zone. Approximately $1.8 \times 10^{12}$ kilograms of explosive energy will be released from a magnitude 9 earthquake. It destroys most of the unprotected infrastructure within several tens of miles in diameter from the epicenter. People can feel the earthquake even if living hundreds of miles away. This study is a seismic simulation analysis for an innovated and improved design of viscoelastic damping isolator, which can be more effectively applied to earthquake prevention and damage reduction of high-rise buildings, roads, bridges, power generation facilities, and so forth, from earthquake disaster. Solidworks graphic software is used to draw the 3D geometric model of the viscoelastic isolator. The dynamic behavior of the viscoelastic isolator through shock impact of specific earthquake loading, recorded by a seismometer, is obtained via ANSYS finite element package. The amplitude of the isolator is quickly reduced by the viscoelastic material in the device and is shown in a time response diagram. The result of this analysis can be a crucial reference when improving the design of a seismic isolator.
\end{abstract}

\section{Introduction}

Seismic isolator is a very important device to reduce the shock vibration transmitted to the buildings, equipment, transportation facilities, and so forth during earthquake. Different types of isolator such as rubber, spring, slide, rotary, and low viscosity liquid flow style are used in different environments. An important technology of reducing the vibration from sudden excitation is viscoelastic damping isolator (VDI) which can be widely used in manufacturing, electricity and gas supply, construction, transportation, and other industries. The use of viscoelastic dampers (VEDs) in high performance earthquake resistant structural systems could be effective in reducing seismic-induced responses [1].

$\mathrm{Ou}$ et al. analyzed the seismic responses of a singlestorey structure and a multistorey structure with the viscous and viscoelastic dampers to verify the effectiveness of the passive energy dissipation devices for suppression of dynamic responses of structures and the reliability of the proposed simplified computational methods [2]. Xu used the equivalent standard solid model of viscoelastic (VE) dampers to describe the energy absorption features of VE dampers. Elastoplastic time field analysis, frequency field analysis, and shaking table tests were used to analyze responses of a $1 / 5$ scale three-storey reinforced concrete frame structure [3]. The damping in cocured composite laminates with embedded viscoelastic layer was determined based on mode superposition and modal strain energy method [4]. Kandemir et al. investigated seismic retrofit of an existing steel arch bridge using viscous damper. Dynamic characteristics along both longitudinal and transverse directions of the bridge were analyzed by eigenvalue analysis to figure out the natural behavior under the dead load [5]. Ohsaki et al. investigated a reverse rocking response for a steel frame using a simple flexible base model consisting of truss elements. Seismic responses of the frame could be further reduced by installing viscous dampers at the support [6]. Tuned mass dampers are widely used to reduce the impact of dynamic excitations on structures. Steinbuch proposed an optimization of earthquake resistance of high buildings by multituned mass dampers via bionic algorithms [7]. Greco and Marano deal with parameter identification for basic and generalized Kelvin-Voigt and Maxwell 
models for fluid viscous dampers [8]. They also conducted a numerical investigation on a simple one degree of freedom structure, equipped with fluid viscous dampers.

Other researchers study seismic response via different isolators and methods. Hejazi et al. developed a threedimensional elastoplastic viscous damper element, consisting of elastic damper in the middle part and two plastic hinges at both ends of the elements which were compatible with the constitutive model to reinforce concrete structures and were capable of detecting failure and damage to the inviscous damper device during earthquake excitation [9]. Hatzigeorgiou and Pnevmatikos proposed a simple and effective evaluating method for these maximum values using the inelastic velocity ratio [10]. This ratio was a modification factor which allowed the evaluation of the maximum inelastic velocity or damping force from their corresponding elastic counterparts. Qin et al. accomplished seismic responses of the nuclear power plants (NPPs) isolated by a friction damper isolation system (FDIS) by means of the finite element approach and setting up a representative multiparticle model of NPPs [11]. Pan et al. proposed a unified approach for long-term behavior and seismic response analysis of alkali-aggregate reaction (AAR) affected concrete dams by combining AAR kinetics, effects of creep, and plastic-damage model in the finite element method [12]. Luco obtained simple analytical expressions for the deformation of the base isolation system and of the superstructure at resonance that were in terms of an effective replacement oscillator characterized by amplitude dependent frequency, damping ratio, and excitation [13]. Numerical results suggest that the seismic response of a structure resting on an inelastic base isolation system might be larger when the flexibility of the soil was considered. Contento and Di Egidio considered the use of base isolation applied to rigid bodies placed on a multistorey frame with the aim of understanding whether or not seismic isolation was beneficial in preventing their collapse during an earthquake [14]. Turk presented the analytical study on the dynamic response of a natural stone block masonry minaret of a historical mosque [15].

Finite element method (FEM) is a common technique to analyze mechanical structure [16]. Huang et al. investigated dynamic characteristics of the viscoelastic damping isolator under impact loading through FEM and experimental analysis [17]. Impact-loading-induced vibration transmitted to the supporting medium could become the governing factor of the foundation of the production machinery [18]. Alva and Gangadharan applied ANSYS harmonic analysis to model a tuned mass absorber which was used to suppress the vibrations from harmonic excitation [19].

This research studies the normal mode vibration and seismic response of the VDI system by employing FEM to simulate the energy dissipation of the device.

\section{Finite Element Analysis}

The VDI is designed to support machinery equipment over 3 tons. It composes 3 plates, 8 partitions, 14 springs, and viscoelastic lipid filled between plates and partitions. The optimal number of plates and springs depends on the weight
TABLE 1: Mechanical properties of the components of VDI.

\begin{tabular}{lccc}
\hline Material & $\begin{array}{c}\text { Young's modulus } \\
(\mathrm{MPa})\end{array}$ & Poisson's ratio & $\begin{array}{c}\text { Density } \\
\left(\mathrm{g} / \mathrm{cm}^{3}\right)\end{array}$ \\
\hline $\begin{array}{l}\text { Low carbon steel } \\
\text { (S25C) (top plate) }\end{array}$ & 210,000 & 0.3 & 7.85 \\
\hline $\begin{array}{l}\text { Spring steel } \\
\text { (SUP-9) }\end{array}$ & 207,000 & 0.29 & 7.0 \\
\hline $\begin{array}{l}\text { PDMS material } \\
\text { (viscoelastic lipid) }\end{array}$ & 1.35 & 0.49 & 0.91 \\
\hline
\end{tabular}

of the facility. The 3D diagram of the VDI is drawn in Solidworks and then is imported into ANSYS software. The dimension and probe location of the measured response acceleration are shown in Figure 1. The plates (partitions), springs, and viscoelastic lipid are assumed to be low carbon steel, spring steel, and polydimethylsiloxane (PDMS), respectively. Corresponding Young's modulus, Poisson's ratio, and density of the above three parameters are shown in Table 1. PDMS is a very soft material to represent the viscoelastic lipid. According to the research of Mathers et al., the damping ratio for PDMS material is $12.3 \%$ [20]. Hence, the modal damping ratio is assumed to be $10 \%$ in the VDI model. ANSYS Solid187 (a higher-order, 3D, 10-node element) is chosen for both of the plates and spring steel. Solid186 is a higher-order, 3D, 20-node solid element which supports plasticity, hyperelasticity, creep, stress stiffening, large deflection, and large strain capabilities. Hence, Solid186 can represent nonlinear viscoelastic behavior of PDMS. These two kinds of elements are suitable for irregular grid also. Figure 2 shows the boundary conditions and mesh of the 3D VDI. The gravity force is applied to whole body of VDI and its bottom plate is supported by the ground with frictionless contact condition between the bottom plate and the ground.

The convergence of the VDI system is examined before normal mode and impact analysis. From convergence plot as shown in Figure 3, the fundamental frequency of the VDI is converged after 65,000 elements. Hence, 70,000 elements are used for the following normal mode and seismic response analysis.

2.1. Normal Mode Analysis. ANSYS modal module is employed to execute the normal mode analysis. The boundary conditions of the VDI are fixed only at the bottom plate but free elsewhere. The modes are normal in the sense that they are independent of each other; that is, an excitation of one mode will never cause motion of a different mode. In mathematical terms, normal modes are orthogonal to each other. The most general motion of the VDI system is a superposition of its normal modes.

2.2. Seismic Response Analysis. Yang et al. employed acceleration time history recorded at Wolong station in the Wenchuan earthquake to excite the model wall [21]. Similar to Yang's work, time history of the earthquake impact acceleration function is introduced at the bottom plate of VDI to examine the seismic response of the system in this paper. 


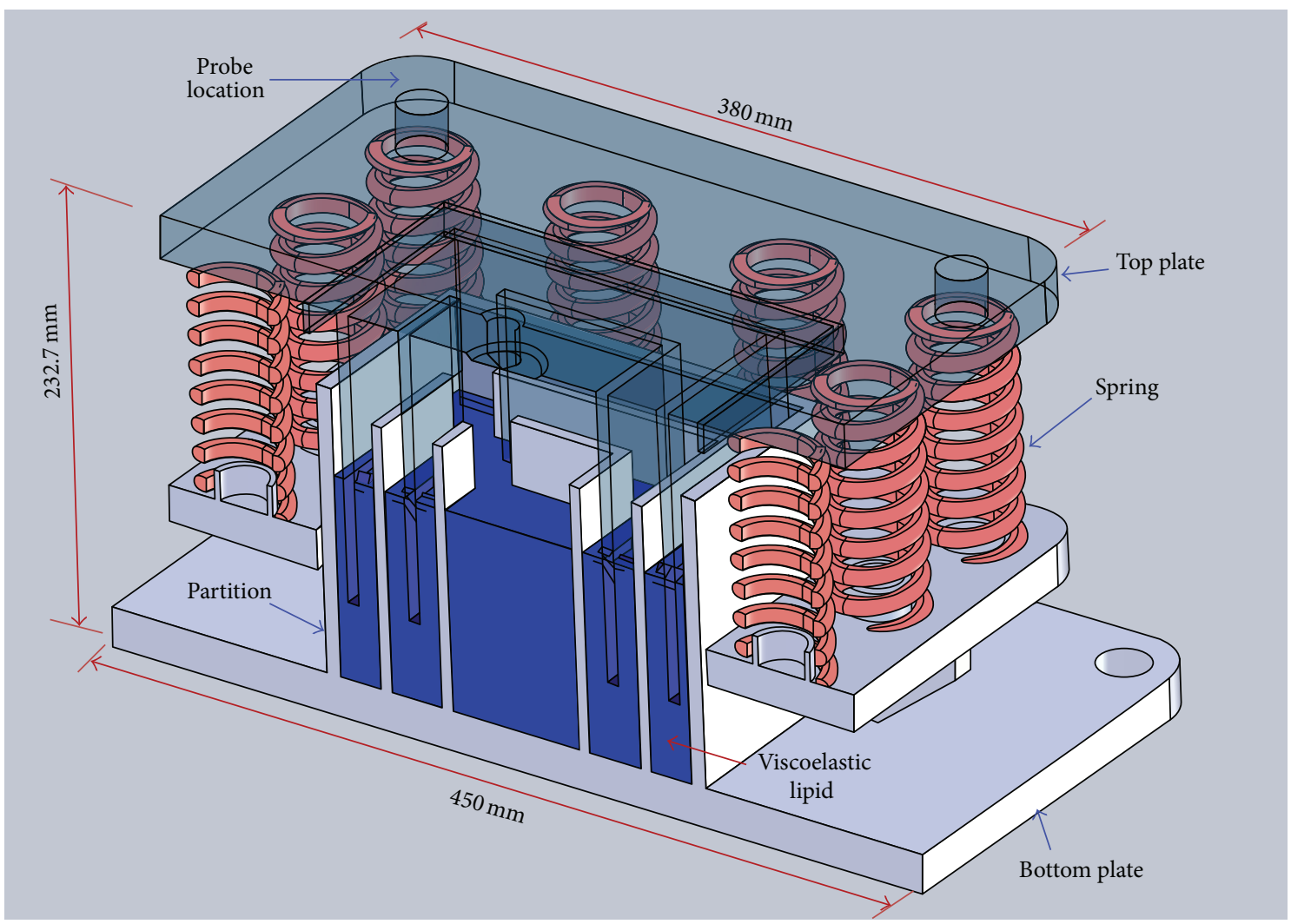

FIGURE 1: The transparent 3D structure of the VDI.

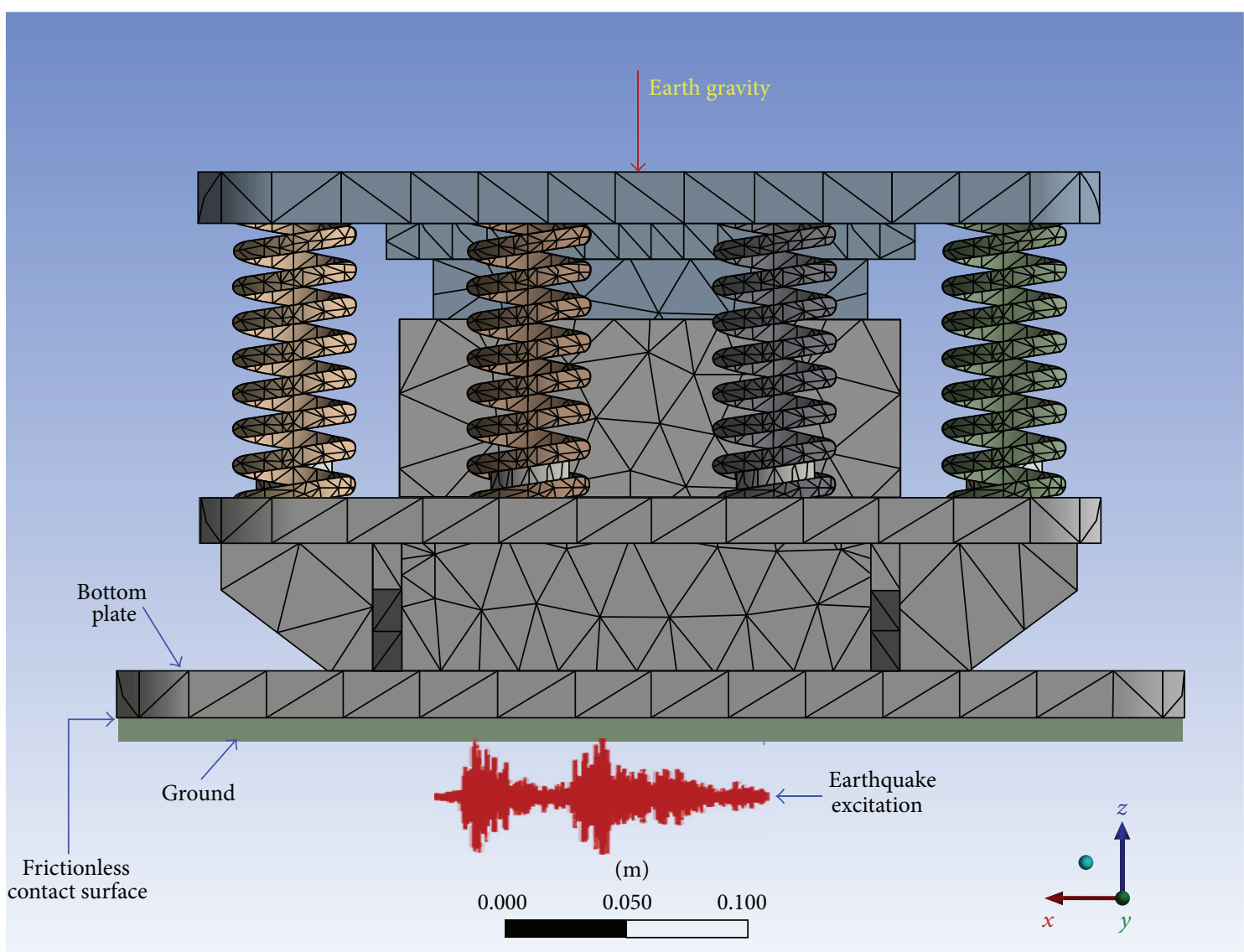

FIGURE 2: Boundary conditions and mesh diagram of the viscoelastic damping isolator. 


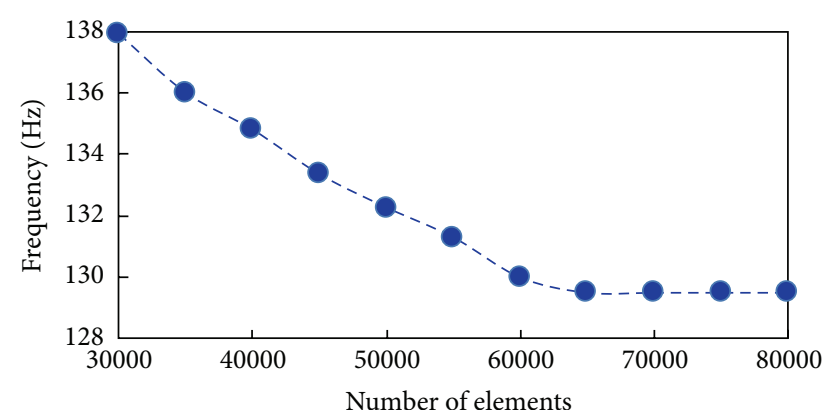

Figure 3: Convergence plot of the VDI system.

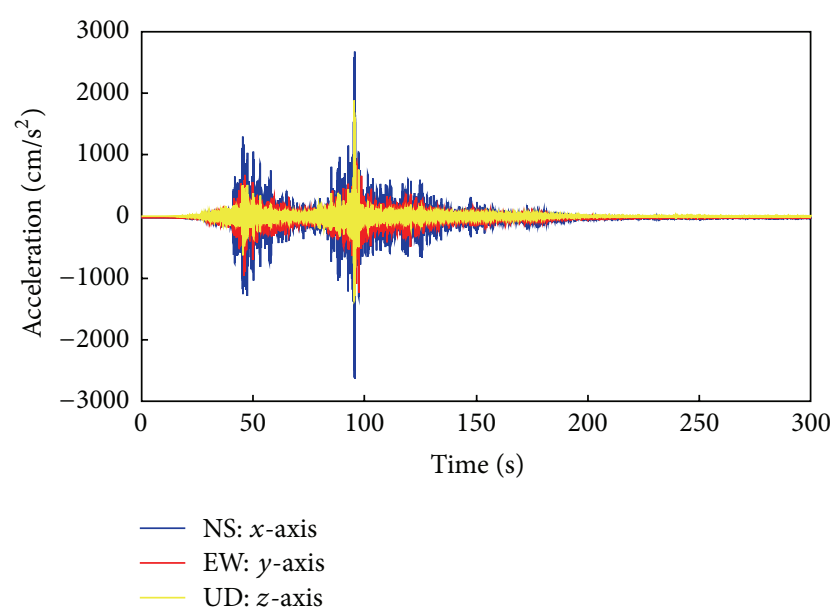

FIGURE 4: Time history of the earthquake occurred at 14:46:00, Mar. 11, 2011, in Tohoku, Japan.

Three directions, north-south (NS, $x$-axis), east-west (EW, $y$ axis), and up-down (UD, $z$-axis) of seismic motion data of Tohoku, Japan, occurring at 14:46:00, Mar. 11, 2011, magnitude 9.0, are obtained from the Center for Engineering Strong Motion Data supported by U.S. Geological Survey (USGS). Time history of Tohoku, Japan, earthquake archived 30,000 records in 300 seconds, as shown in Figure 4. The calculation and memory resources will be exhausted if one imports the whole 300-second data into the desktop PC. Therefore, only 30 seconds of data near the second pick of the earthquake, around 80 to 100 seconds, are chosen to be the seismic excitation input for the VDI system. In this case, the gravity force is applied to whole body of VDI. The bottom plate of VDI system is supported frictionless by the ground and is applied by the Tohoku earthquake acceleration function for the transient seismic analysis. However, there is no huge equipment mass applied to the top of VDI. It is only for pure investigation of the response of damper under earthquake attack.

\section{Results and Discussion}

The results obtained from the seismic analysis are discussed in two parts: normal mode analysis and seismic response analysis.
TABLE 2: Six fundamental natural frequencies of the VDI.

\begin{tabular}{lcccccc}
\hline Normal mode & 1 & 2 & 3 & 4 & 5 & 6 \\
\hline Natural frequencies (Hz) & 129.5 & 134.3 & 181.3 & 190.0 & 195.2 & 195.8 \\
\hline
\end{tabular}

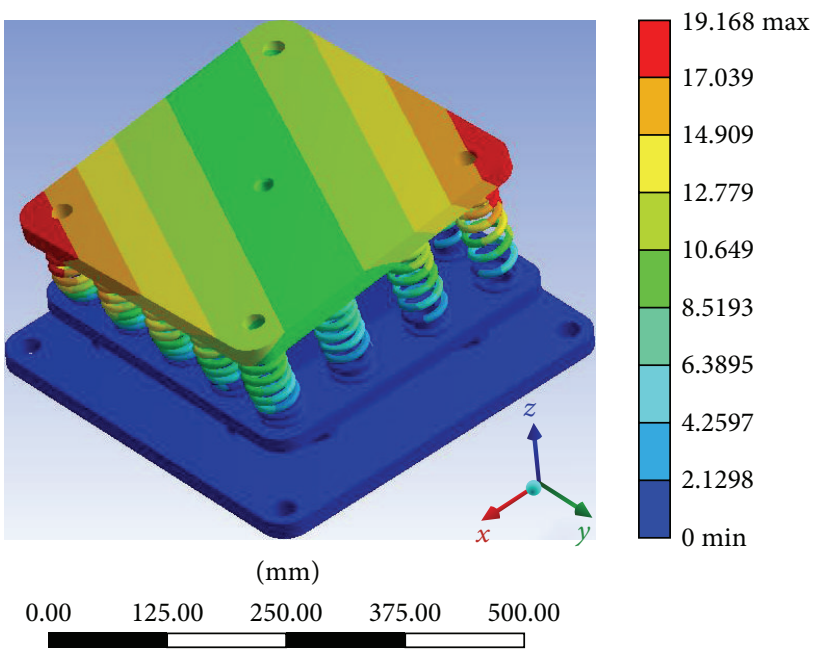

Figure 5: The first mode is a rolling mode of the top plate in $y$-axis at $129.5 \mathrm{~Hz}$.

3.1. Normal Mode Analysis. Six fundamental natural frequencies of the VDI are shown in Table 2. The first mode is a rolling mode of the top plate on $y$-axis at $129.5 \mathrm{~Hz}$, as shown in Figure 5. The second mode is a rolling mode of the top plate on $x$-axis at $134.3 \mathrm{~Hz}$. The third mode is an up-down mode of the top plate on $z$-axis at $181.3 \mathrm{~Hz}$. The fourth mode is a yawing mode of the top plate in $x y$ plane at $190 \mathrm{~Hz}$, as shown in Figure 6. The fifth and sixth natural frequencies are $195.2 \mathrm{~Hz}$ and $195.8 \mathrm{~Hz}$, respectively. The linear combination of sufficient number of normal modes can build up a general motion of VDI system.

3.2. Seismic Response Analysis. Only 30 seconds out of 300 seconds including peak magnitude of time history of the earthquake is imported carefully into ANSYS transient module as the impact function at the bottom plate of VDI to simulate the seismic response of the system. The comparison between the original earthquake time history and seismic responses obtained at the probe location of the corner of top plate in $x, y$, and $z$ directions is shown in Figures 7, 8, and 9, respectively. The peak acceleration values of the earthquake in NS ( $x$-axis), EW ( $y$-axis), and UD ( $z$-axis) are $2,670,901$, and 1,880 gal $\left(\mathrm{cm} / \mathrm{sec}^{2}\right)$, respectively. However, the peak seismic responses at the probe location of the top plate of VDI in NS ( $x$-axis), EW ( $y$-axis), and UD ( $z$-axis) are attenuated to large amounts of $16.5,7.5$, and 20 gal, respectively. Since there is no huge equipment mass placed on top of VDI and the strong stiffness of the spring, the seismic acceleration impact does not cause large deformation of the top plate of VDI. The results show that the peak value of the seismic responses is over 100 times smaller than the original value of the Tohoku 


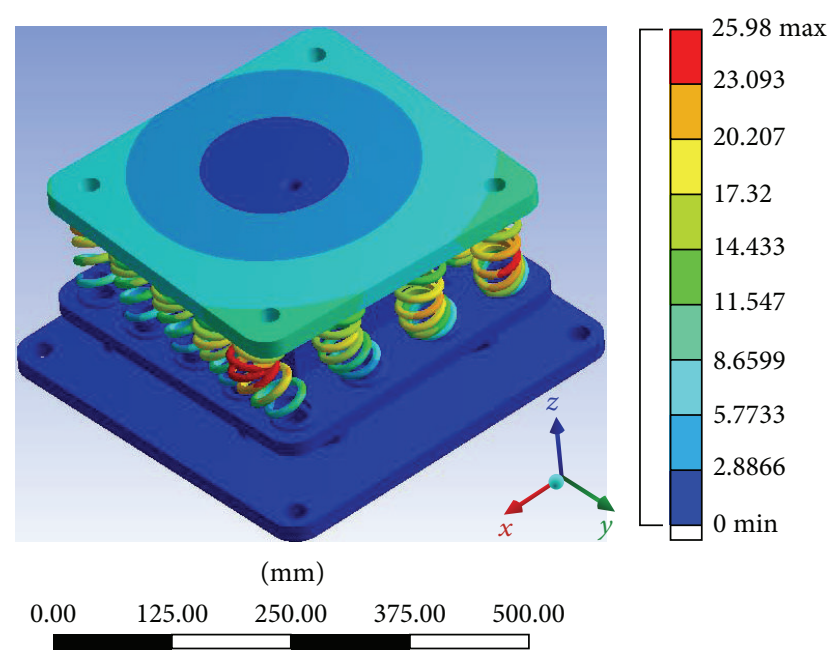

FIGURE 6: The fourth mode is a yawing mode of the top plate in $x y$ plane at $190 \mathrm{~Hz}$.

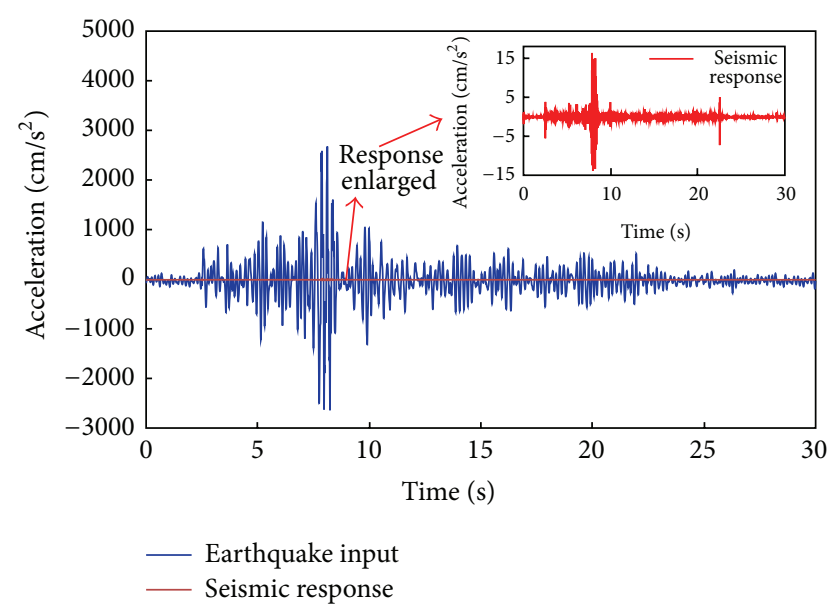

FIGURE 7: Seismic response of VDI system in NS direction ( $x$-axis).

earthquake. The order of the attenuation is in NS ( $x$-axis), EW ( $y$-axis), and UD ( $z$-axis) directions sequentially.

\section{Conclusion}

This research studies the normal mode vibration and seismic response of the VDI system by using FEM. The obtained results are summarized as follows.

(1) Normal mode vibration of the VDI is obtained. The linear combination of sufficient number of normal modes can build up a general motion of VDI system. It is useful for the future design in altering the natural frequencies of VDI.

(2) The VDI system can dissipate the seismic energy in huge amount smaller than the original peak acceleration of the Tohoku earthquake in all $x, y$, and $z$ directions when there is no equipment mass located on top of VDI.

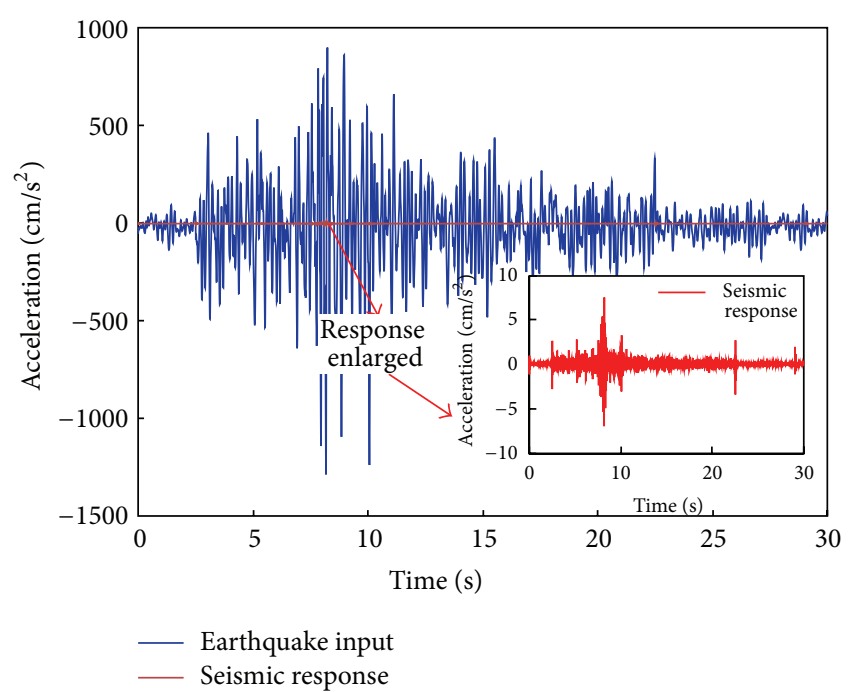

FIGURE 8: Seismic response of VDI system in EW direction ( $y$-axis).

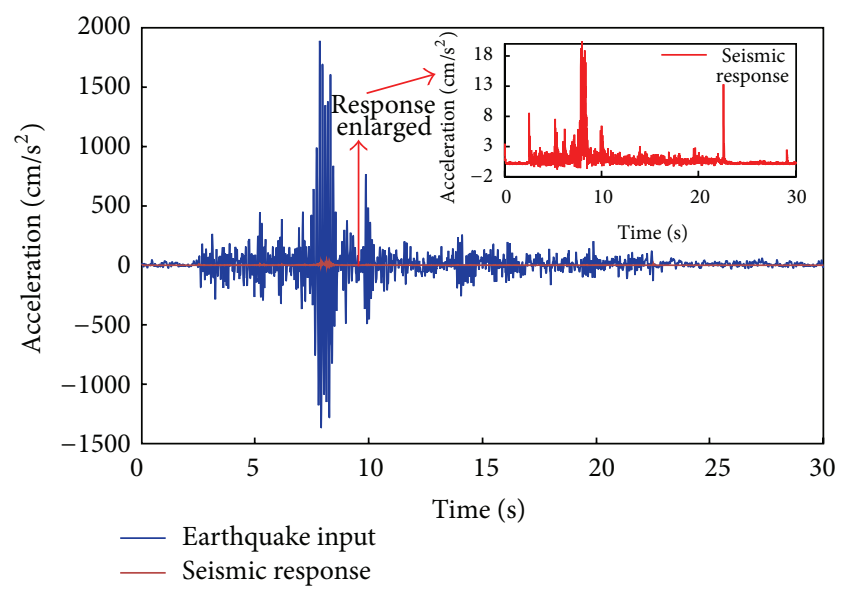

FIGURE 9: Seismic response of VDI system in UD direction ( $z$-axis).

(3) The results show that the energy of the earthquake is quickly absorbed by the viscoelastic material to attenuate the amplitude of the top plate of the isolator. The order of the attenuation is in NS ( $x$-axis), EW ( $y$ axis), and UD ( $z$-axis) directions sequentially.

\section{Conflict of Interests}

The authors declare that there is no conflict of interests regarding the publication of this paper.

\section{References}

[1] T. L. Karavasilis, T. Blakeborough, and M. S. Williams, "Development of nonlinear analytical model and seismic analyses of a steel frame with self-centering devices and viscoelastic dampers," Computers and Structures, vol. 89, no. 11-12, pp. 1232-1240, 2011. 
[2] J. P. Ou, X. Long, and Q. S. Li, "Seismic response analysis of structures with velocity-dependent dampers," Journal of Constructional Steel Research, vol. 63, no. 5, pp. 628-638, 2007.

[3] Z.-D. Xu, "Earthquake mitigation study on viscoelastic dampers for reinforced concrete structures," Journal of Vibration and Control, vol. 13, no. 1, pp. 29-43, 2007.

[4] L. Pan and B. Zhang, "A new method for the determination of damping in cocured composite laminates with embedded viscoelastic layer," Journal of Sound and Vibration, vol. 319, no. 3-5, pp. 822-831, 2009.

[5] E. C. Kandemir, T. Mazda, H. Nurui, and H. Miyamoto, "Seismic retrofit of an existing steel arch bridge using viscous damper," Procedia Engineering, vol. 14, pp. 2301-2306, 2011.

[6] M. Ohsaki, O. Iwatsuki, and H. Watanabe, "Seismic response of building frames with flexible base optimized for reverse rocking response," Engineering Structures, vol. 74, pp. 170-179, 2014.

[7] R. Steinbuch, "Bionic optimisation of the earthquake resistance of high buildings by tuned mass dampers," Journal of Bionic Engineering, vol. 8, no. 3, pp. 335-344, 2011.

[8] R. Greco and G. C. Marano, "Identification of parameters of Maxwell and Kelvin-Voigt generalized models for fluid viscous dampers," Journal of Vibration and Control, vol. 21, no. 2, pp. 260-274, 2015.

[9] F. Hejazi, A. Zabihi, and M. S. Jaafar, "Development of elastoplastic viscous damper finite element model for reinforced concrete frames," Soil Dynamics and Earthquake Engineering, vol. 65, pp. 284-293, 2014

[10] G. D. Hatzigeorgiou and N. G. Pnevmatikos, "Maximum damping forces for structures with viscous dampers under nearsource earthquakes," Engineering Structures, vol. 68, pp. 1-13, 2014.

[11] C. Qin, W. Liu, and W. He, "Seismic response analysis of isolated nuclear power plants with friction damper isolation system," AASRI Procedia, vol. 7, pp. 26-31, 2014.

[12] J. Pan, Y. Xu, F. Jin, and C. Zhang, "A unified approach for longterm behavior and seismic response of AAR-affected concrete dams," Soil Dynamics and Earthquake Engineering, vol. 63, pp. 193-202, 2014.

[13] J. E. Luco, "Effects of soil-structure interaction on seismic base isolation," Soil Dynamics and Earthquake Engineering, vol. 66, pp. 167-177, 2014.

[14] A. Contento and A. Di Egidio, "On the use of base isolation for the protection of rigid bodies placed on a multi-storey frame under seismic excitation," Engineering Structures, vol. 62-63, pp. 1-10, 2014.

[15] A. M. Turk, "Seismic response analysis of masonry minaret and possible strengthening by fiber reinforced cementitious matrix (FRCM) materials," Advances in Materials Science and Engineering, vol. 2013, Article ID 952497, 14 pages, 2013.

[16] S. Valliappan and K. Qi, "Finite element analysis of a 'smart' damper for seismic structural control," Computers and Structures, vol. 81, no. 8-11, pp. 1009-1017, 2003.

[17] B. W. Huang, J.-G. Tseng, and Y.-L. Ko, "Stress and vibration of a viscoelastic damping isolator under impact loading," Journal of Vibroengineering, vol. 16, no. 5, pp. 2355-2362, 2014.

[18] A. G. Chehab and M. H. El Naggar, "Response of block foundations to impact loads," Journal of Sound and Vibration, vol. 276, no. 1-2, pp. 293-310, 2004.

[19] R. A. Alva and K. V. Gangadharan, "Experimental and finite elements analysis of a tuned mass absorber for vibration isolation," ARPN Journal of Engineering and Applied Sciences, vol. 6, no. 1, pp. 77-83, 2011.
[20] A. Mathers, K. S. Moon, and J. Yi, "A vibration-based PMN-PT energy harvester," IEEE Sensors Journal, vol. 9, no. 7, pp. 731-739, 2009.

[21] C. Yang, J. J. Zhang, Q. Honglue, B. Junwei, and L. Feicheng, "Seismic earth pressures of retaining wall from large shaking table tests," Advances in Materials Science and Engineering, vol. 2015, Article ID 836503, 8 pages, 2015. 

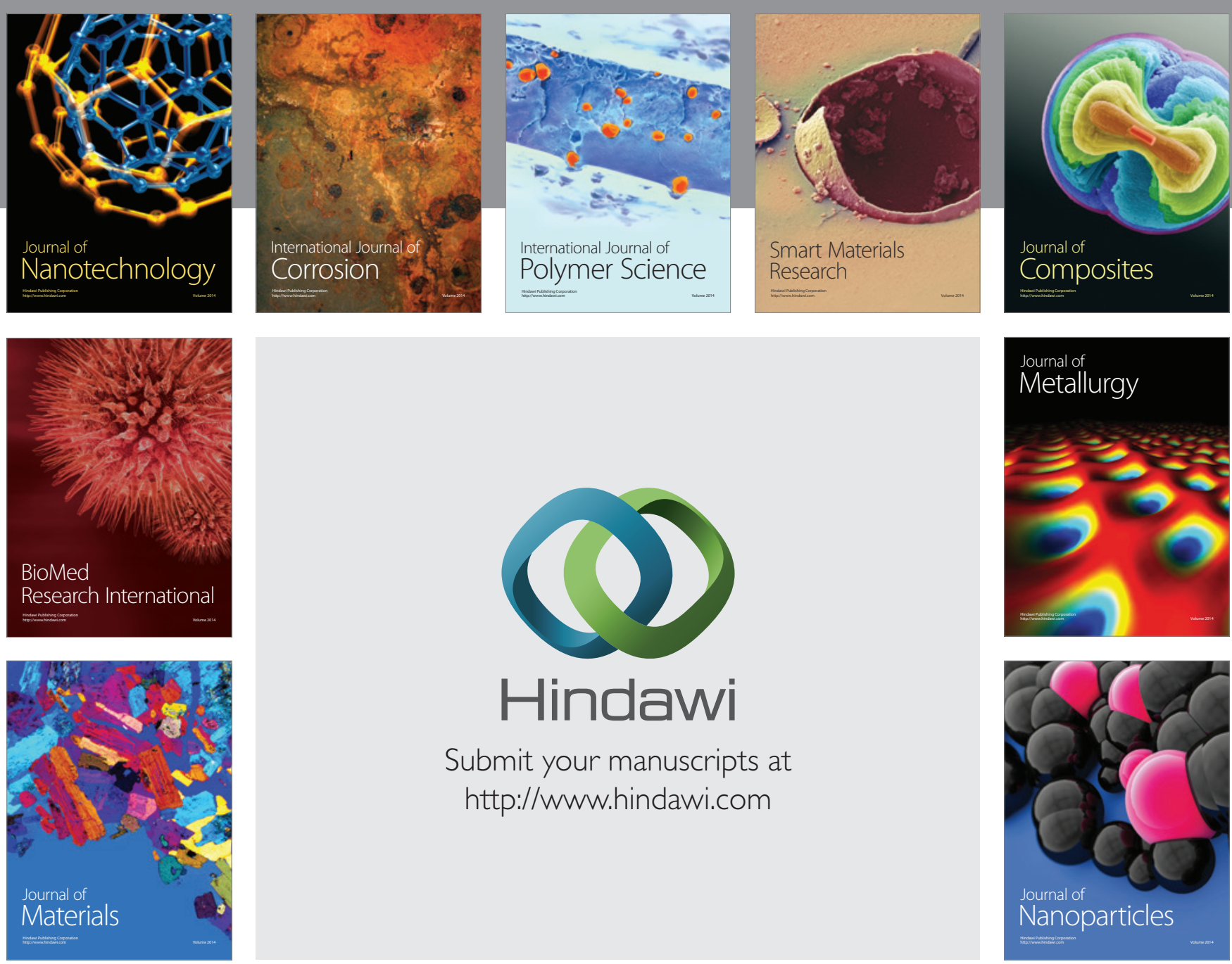

Submit your manuscripts at http://www.hindawi.com
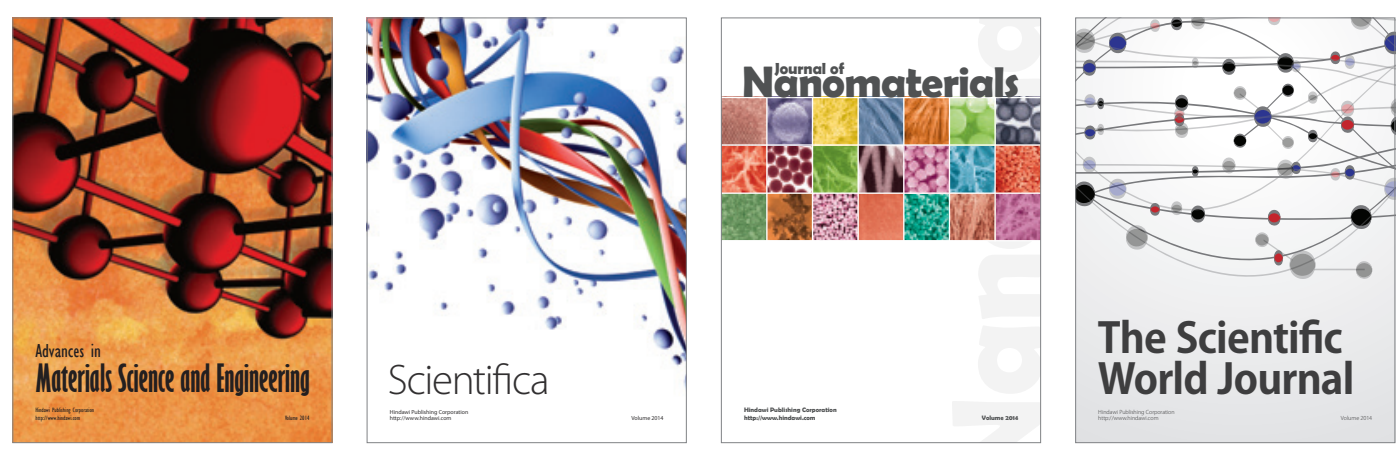

\section{The Scientific World Journal}
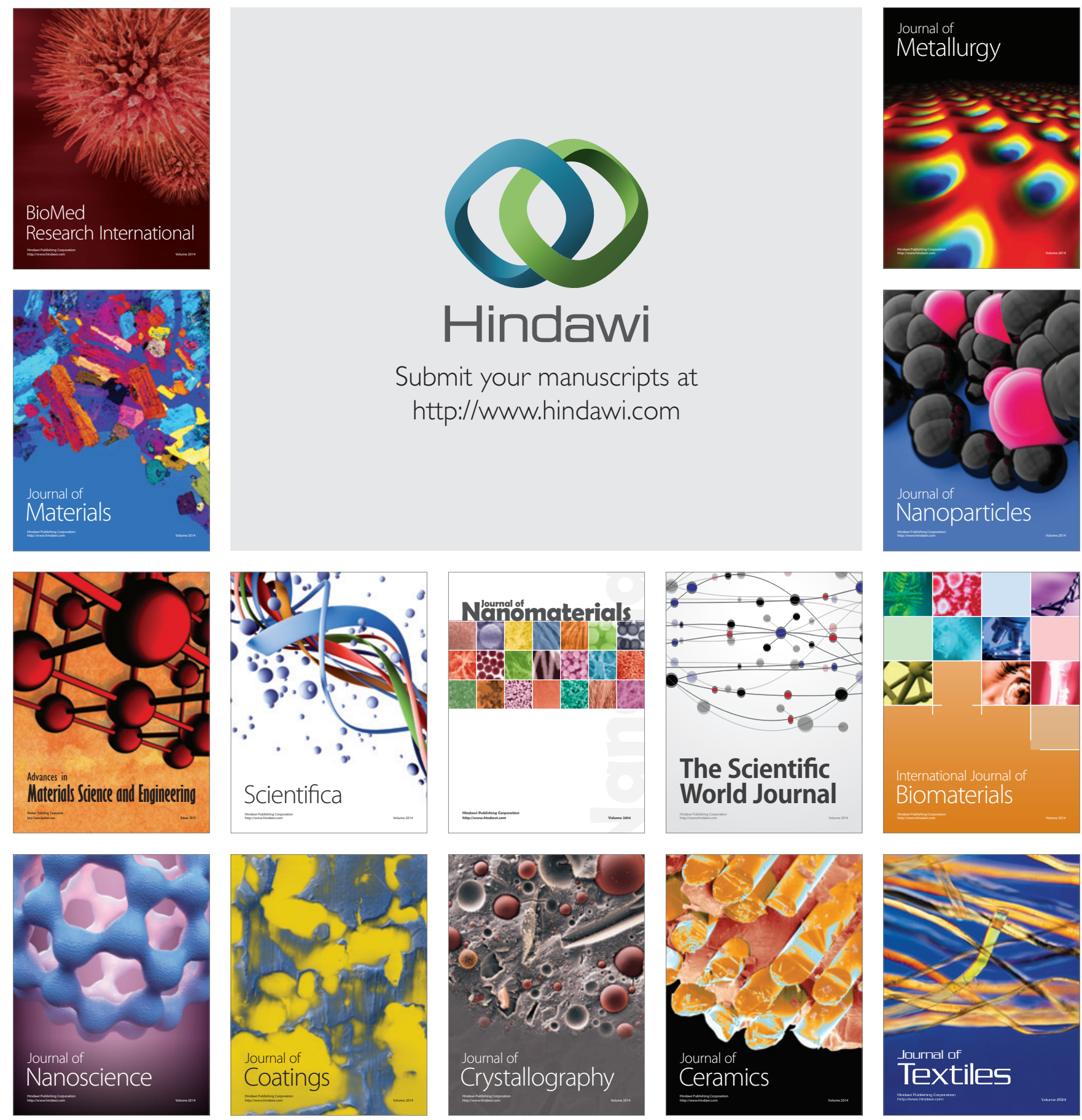